\title{
EDUCAÇÃO INCLUSIVA: UMA HISTÓRIA, UMA CAMINHADA E NOVAS CONQUISTAS PARA O PORTADOR DE NECESSIDADES ESPECIAIS
}

\author{
Benedito Borel da CONCEIÇÃO ${ }^{1}$ \\ Damián S. SÁNCHEZ²
}

Licenciado em Pedagogia pela Universidade do Estado da Bahia UNEB; Licenciado em Artes Visuais pela UNIMESVIRTUAL Santos, São Paulo e Mestre em Gestão Social, Educação e Desenvolvimento Regional. Benedito.borel@uol.com.br

Mestre e Doutor em Educação pela Universidade Federal do Espírito Santo. Docente do curso de Mestrado Profissional em Gestão Social, Educação e Desenvolvimento Regional, Faculdade Vale do Cricaré. munivc@gmail.com

Recebido em: 23/05/2014 - Aprovado em: 30/06/2014 - Disponibilizado em: 30/07/2014

RESUMO: A educação inclusiva tem uma longa história para encontrar condições dígnas para as pessoas se integrarem no meio social e assim erradicar o preconceito junto à sociedade acadêmica, mercado de trabalho e outros meios sociais que impedem o cidadão ou cidadã exercerem o direito de cidadania com dignidade e igualdade. Aliás, a inclusão escolar frente as políticas públicas da esfera federal, estadual e municipal, ainda, é uma realidade crucial, que, vai além de uma matrícula, mas de todo os recursos tecnológicos, pedagógicos, estrutura física da escola, acessibilidade, material humano, formação do professor para mediar o ensino aprendizado com o aluno, construir as habilidades e fazer a inclusão acontecer.

Palavras Chave: Educação Inclusiva, História, Caminhada, Conquistas, Cidadania.

ABSTRACT: Inclusive education has a long history to find decent people to integrate in the social environment and thus eradicate prejudice in the academic society, labor market and other social media to prevent a citizen from exercising the right to citizenship dignity and equality. Moreover, school inclusion public policies across federal, state and municipal level, yet it is a crucial reality that goes beyond a file, but from all the technological resources, educational, physical structure of the school, accessibility, human material, teacher training to mediate teaching with student learning, build skills and make inclusion happen.

Key Words: Inclusive Education, History, Hiking, Achievement, Citizenship.

\section{INTRODUÇÃO}

A educação inclusiva: uma história, uma caminhada e novas conquistas para o portador de necessidades especiais, é um tema, que merece a atenção do Brasil e do mundo. Segundo Mazzotta (2005) A educação inclusiva tem uma longa caminhada que teve início no século XVII. Até esse período não havia base cientifica para estudo de caso que pudesse estudar, compreender e avaliar a condição física e mental dos portadores de necessidades especiais naquela época.
Entretanto, tal situação, ignorada, causava inquietação a um grupo de pessoas que se angustiava ao ver seres humanos sem valor para a sociedade ou considerados inúteis. Até mesmo os religiosos da época não viam o deficiente como ser que merecia o respeito, pois se acreditava que o homem deveria ser perfeito por ser imagem de Deus e ter sua semelhança.

Ainda, segundo Mazzotta (2005), somente quando o homem teve condições de perceber 
outro considerado perfeito, foi que começou a defesa dos interesses em favor do deficiente. Mas, é importante ressaltar que naquele período as pessoas que se posicionavam em favor do deficiente eram homens, mulheres, leigos, deficientes que exerciam o papel de líderes no meio social onde viviam e que almejavam melhores condições de vida para todos os que os cercavam.

Já no século XIX, na Europa, emergiam os primeiros passos para o atendimento ao portador de necessidade especial e esse movimento que emergiu na Europa se adentrava pelos Estados Unidos da América, Canadá, Brasil e outros países continentais. A partir dessa movimentação os deficientes conquistam direitos e deveres de serem cidadãos reconhecidos como gente em pé de igualdade, porém ainda era tímido o atendimento.

Diversas expressões eram utilizadas no século XIX quando se referiam ao portador de necessidade especial naquela época, assim como as pedagogias predominantes: Pedagogia Curativa, que tinha como objetivo o método de curar o deficiente ou portador de necessidade especial de sua síndrome ou anomalia; Pedagogia Social, que tinha o objetivo de curar o deficiente e devolvê-lo curado à sociedade, entre outras pedagogias voltadas a atender o portador de necessidade especial, mas sem compreender o verdadeiro significado da inclusão do homem, mulher ou criança que se encontrava inútil em pleno espaço social.

$\mathrm{Na}$ Alemanha, esse movimento iniciou na cidade de Munique, atendendo a educação de deficientes físicos na fundação que encarregava em ensinar algumas pessoas que tivessem algumas sequelas consideradas deficiência física, o que naquele século era considerado um grande avanço na área social e educacional para pessoas de baixo poder aquisitivo e também pessoas da prole intelectual.

Esse trabalho deu sequência a uma longa jornada na busca de implementação para adequar melhor a educação inclusiva e também o seu público alvo com a ajuda de alguns estudiosos, entre tantos: Maria Montessori, que contribuiu para a evolução da educação especial com metodologia concreta que ganhou repercussão nos diversos segmentos da educação e seu material didático ficou assim conhecida como material dourado, capaz de promover a inclusão escolar.

Já na década de 1950, a educação inclusiva ganha espaço mais acelerado nas instituições públicas e privadas, os Estados do Brasil, que, ganharam repercussão naquele certame foi na capital do Paraná e a cidade de Londrina, cidades essas consideradas evoluídas e que seriam modelo nesse atendimento no Brasil. Porém, vale ressaltar, que, a educação 
inclusiva ganha espaço em uma época considerada populista nos anos de (1955 e 1964) período da ditadura militar no Brasil. Naquela década, o Congresso edita a LDB 4024/61 que reafirma o direito dos excepcionais no Art.88, que teve sua revogação pela Lei 9394/96

Artigo 88. A União, os Estados, o Distrito Federal e os Municípios adaptarão sua legislação educacional e de ensino às disposições desta Lei no prazo de máximo de um ano, a partir da data de sua publicação.

LDB 9394/96 de 20 de dezembro de 1996.

Portanto, Mazzotta (2005) afirma que, o Brasil continuou avançando na área da educação, quando a partir de 1971 o Congresso Nacional aprova a nova Lei $5692 / 71$, com redação alterada pela Lei $\mathrm{N}^{\mathrm{o}}$ 7.044/82 e assegura o tratamento especial para os alunos que apresentam deficiências físicas, mentais, aos alunos com idade defasada considerando ao período de ingressar no ensino de $1^{\circ}$ grau e os alunos considerados superdotados têm garantia no Artigo 88 da Lei 4024/61 e enquadra os alunos com necessidades especiais no sistema geral de educação. Assim a Lei No 4024/61 de 20 de dezembro de 1961, a Lei $n^{\circ}$ 9.131, de 1995. Fixa as diretrizes e Bases da Educação Nacional. Artigo 88 e 89 (revogados pela Lei $\left.n^{\circ} 9394 / 96\right)$
Esse foi considerado um grande avanço para educação nas diferentes modalidades de ensino, a saber: educação inclusiva para portadores de necessidades especiais. Entretanto, vale ressaltar, que, as conquistas para os portadores de necessidades especiais e que os argumentos sobre o caminho percorrido pela educação inclusiva até a década de 1990 foi árdua, porém aponta a história de um povo e as conquistas rumo ao reconhecimento das políticas públicas dos diversos segmentos governamentais e filantrópicos

As observações aqui apresentadas não apontam, todavia, a retirada ou diminuição da validade da política traçada nas Portarias Interministeriais analisadas. Apenas registram sua direção. Naquele momento, as diretrizes para uma ação integrada entre os Ministérios envolvidos representaram, por certo, a busca de rumos e a delimitação de campos de atuação governamental com vistas à melhoria do atendimento aos excepcionais. Entretanto, tendo-se em conta que "a atitude do bem democrático é a de não se iludir com o melhor e a de não se resignar com o pior" e considerando os próximos do presente. Nessa medida, elas revelam uma tendência de configuração da educação especial no campo terapêutico, preventivo, corretivo e não no pedagógico ou mais especificamente escolar (MAZZOTTA, 2005, p. 73). 
Assim, a história da educação especial não está fundamentada apenas na legislação, mas num conjunto de ações voltadas a articular políticas de prevenção, capaz de garantir aos alunos portadores de necessidades especiais o direito de serem diferentes e sujeito íntegro na comunidade escolar.

\section{NOVAS CONQUISTAS PARA O PORTADOR DE NECESSIDADES ESPECIAIS}

Para entender o significado da palavra conquistas é preciso buscar ajuda no dicionário e compreender que é uma particularidade de alguma coisa que se consegue, ganha numa determinada luta, ou que antes não se concebia. Assim, Emilio (2008) defendia que todos os alunos com necessidades especiais deveriam ser inseridos nas classes comuns de alunos "considerados regulares", possibilitar a, manutenção dos serviços de ensino especial ou atendimento diversificado aos portadores de diferentes síndromes ou outras deficiências dentro do âmbito da sala de aula. Entretanto, ainda se faz necessário reformar a escola ou reformar a educação com todos os seus seguidores para entender a outra história da educação inclusiva.

É preciso que a comunidade escolar entenda a diferença de cada indivíduo e sua particularidade. Convicto que no Brasil a maioria dos educadores das redes públicas e rede privada de ensino, seus profissionais que atuam no ensino fundamental $\mathrm{I}$ ou $1^{\circ}$ ao $5^{\circ}$ ano são licenciados em pedagogia, sendo que essa graduação não dá suporte ao profissional para visualizar com olhar científico e ser capaz de diagnosticar tal ou tais anomalias, surge então os questionamentos: o que fazer com esse aluno ou aqueles alunos? Quem pode me ajudar? Preciso conversar com o pai ou responsável, afinal o que devo fazer para erradicar o preconceito na sala de aula? É preciso conhecer a outra face da educação inclusiva, é preciso compreender a legislação, é preciso compreender o que fazer e como fazer para superar o medo e conviver com a realidade, produzir efeitos eficientes capazes de transformar a exclusão em ações libertadoras.

Ainda, segundo Emilio (2008), na escola regular a criança portadora de necessidade especial é capaz de integrar-se ao grupo de alunos "considerados regulares" e ter aproveitamento significativo. Porém, é preciso conhecer a legislação e como fazer a integração nas classes regulares, os números de crianças a serem assistidos, os mobiliários, iluminação, material didático, o número de crianças consideradas regulares, as atividades consideradas diversificadas, um professor coadjuvante para que a turma seja bem assistida e possa assim acontecer a construção do conhecimento. 
De acordo com os argumentos de Mazzotta (2005, p. 68) A as conquista do Brasil no âmbito da educação inclusiva tem sido vasto, porém ainda se tem muito que fazer, o país viveu vários períodos na sua história, muitas leis foram promulgadas e outras foram revogadas, mas os balanços positivos no que discute a inclusão de pessoas portadoras de necessidade especial foram grandes as conquistas, iniciando pelas salas de alunos regular onde o aluno portador de necessidade especial encontrou abrigo e pode assim começar a construir a sua história.

No entanto, a conquista na educação especial não se findou no tempo e nem no espaço, nos dias contemporâneos os governos dos Estados, os governos dos municípios, o governo federal, tem transferido recursos para as secretarias de assistência social, secretaria de educação, têm assinado convênios com órgãos governamentais, empresas da área privada com fins específicos de atender às demandas da educação especial nos diversos recantos do território nacional.

No encontro realizado na Espanha nos dias 7 e 10 de junho de 1994, que culminou com a Conferência Mundial de Educação Especial organizada pelo governo da Espanha e em cooperação com a UNESCO. Seu objetivo foi informar sobre as políticas e ações governamentais, de organização não governamental e outras sobre os princípios, políticas e práticas em educação especial. A estrutura baseia-se nas experiências dos países participantes, representando 88 governos e 25 organizações internacionais, gerando assim oportunidades para pessoas com deficiências (BRASIL, 1996).

Mittler (2003, p.34), afirma que a "integração para a inclusão é muito mais que uma mudança". Foi uma tomada de decisão de chefes de estados e demais simpatizantes com a causa da inclusão de portadores de deficiência, que após os acordos celebrados em Salamanca, o mundo passou a conhecer os dados alarmantes da deficiência que precisavam ser incluídos no meio social, haja vista que naquela época havia mais de 100 milhões de crianças, incluindo-se cerca de 60 milhões de meninas, que não tinham acesso à escolarização primária.

Dos 600 milhões de pessoas com deficiência no mundo, 150 milhões estavam com menos de 15 anos de idade, sendo que menos de $2 \%$ dessas pessoas recebiam qualquer modalidade de educação, apesar dos esforços e das recomendações de organismos nacionais e internacionais. Acredita-se que a Conferência de Salamanca foi o fio condutor para que, as autoridades se preocupassem com a situação lamentável chamada exclusão.

Após todas as discussões e ações os anos 80 e 90 podem ser considerados de conquistas e transformações da educação nacional, ou um marco histórico no qual se registraram 
importantes tentativas de enfrentamento do desafio de que todas as escolas, como integrantes do contexto social criem melhores oportunidades de aprendizagem básica para todas as crianças, adolescentes, jovens e adultos, tal como preconizado na Declaração Mundial sobre Educação para Todos (Jomtien-Thailandia, 1990).

Esses fatos sociais, associados aos dados estatísticos referentes ao quadro internacional, de cores tão sombrias, evidenciaram a necessidade de se emergir os direitos das pessoas com necessidades especiais. $\mathrm{O}$ encontro de Salamanca ocorreu para alertar e para assegurar que aprendizes com necessidades educacionais especiais sejam incluídos nos planos locais e nacionais de educação assegurando-lhes a abertura de todas as escolas, que devem se transformar em centros prazerosos de ensinoaprendizagem.

Assim, na Conferência de Salamanca foram estabelecidos como os principais objetivos: a inclusão de todas as crianças do mundo nas escolas e a reforma do sistema educacional para tornar esse objetivo possível. Embora essas questões sejam centrais para a democratização da educação, não suscitavam as atenções conferidas a outros temas tais como o financiamento da educação ou a avaliação do rendimento escolar, por exemplos.
$\mathrm{Na}$ organização dos trabalhos, 4 (quatro) temas foram estruturantes da Conferência: Política e Legislação; Perspectivas Escolares; Perspectivas Comunitárias e Parceria e Construção de Redes. Ocorreram palestras seguidas de discussões em grupos e sessões plenárias para análise das contribuições dos grupos. Porém, deve perceber que todas as discussões, seminários, plenárias, realizadas em favor da inclusão nos ambientes sociais que o portador de deficiência estiver, o indivíduo deve perceber que essa oportunidade não é única e nem irrestrita, mais uma conquista que vem caminhando desde o século XVIII e que só agora no Brasil, emerge a discussão e trilha caminhos pela emancipação da inclusão nas escolas públicas, escolas privadas, centro de inclusão mantido pelos governos das esferas municipal, estadual, outros centros, conta com o apoio da união, isso se faz para garantir o que rege a Declaração Universal dos Direitos Humanos e dar legitimidade a legislação nacional como: Constituição Federal de 1988, LDB/9394/96, Estatuto da Criança e a Lei que garante o acesso e permanência do portador de necessidade especial em espaços e dependências públicas nos diversos seguimentos da sociedade.

Essas discussões permitiram que o Brasil acelerasse a legislação como a edição da nova LDB 9394/96 de 20 de dezembro de 1996, o qual foi considerado um marco para a 
educação brasileira, o que confere no Art.58 que assegura a educação.

Segundo, CIBEC/MEC (2010), a educação inclusiva ganha um novo cenário e uma nova dimensão nos debates da educação nacional, os propõem revitalização, orientação de apoio técnico e financeiro da iniciativa pública e no âmbito da iniciativa privada, no sentido de propiciar novas condições de atender ao público alvo em condições de recursos didático, acessibilidades nas escolas de forma a promover a igualdade de condições a todos os alunos da rede pública e rede privada de ensino.

Diante do exposto, as facetas da inserção da educação inclusiva no âmbito escolar, ganha um novo olhar e nova dimensão no contexto da escola e adentra a sala de aula para permitir à aqueles ou aquelas famílias que tem filhos portadores de necessidades especiais, que, possam matricular seu filho na escola e ter o conhecimento que a criança portadora de necessidade especial tem direitos iguais ao aluno regular.

\section{CONCLUSÃO}

Neste trabalho objetivou-se a conhecer uma história, uma caminhada e nova conquistas para o portador de necessidades especiais nas salas regulares e o desempenho cognitivo delas no âmbito escolar da instituição pública da educação básica, a fim de analisar de que maneira estão acontecendo às diretrizes de inclusão na escola e se a inclusão está provocando mudanças nas estruturas psicológicas, sociais, cognitivas, afetivas das crianças portadoras de necessidade especiais das escolas da educação básica.

A descrição e análises sobre a educação inclusiva e os alunos considerados portadores de necessidades especiais, ainda, a investigação dos maiores entraves enfrentados pelos professores para a construção de uma educação inclusiva, que garante ao aluno os direitos conferidos no "Decreto Lei n". 3.298, de 1999, que regulamenta a Lei no 7.853, de 24 de outubro de 1989, que dispõe sobre a Política Nacional para a Integração da Pessoa Portadora de Deficiência” que também serviu de embasamento para esse artigo.

Compreender as demandas que os professores e demais envolvidos com a educação básica no âmbito escolar do ensino regular, implicou-se em adentrar pelo universo das concepções dos professores, diretores, coordenadores pedagógicos, pessoal da área administrativa: serviçal, secretário escolar, porteiro, professor de disciplina, sobre a realidade desse campo educacional que integrou esses novos cidadãos mirins dentro da sala e a pertencer a essa nova família ora denominada alunos portadores de 
necessidades especiais nas salas regular de ensino.

Porém, tais medidas adotadas, o período de permanência na sala de aula com recreação para integração da criança portadora de necessidades especiais aos grupos de alunos considerados regulares, atividades lúdicas para estimular o raciocínio lógico, construção de atividades diversificadas para atender cada aluno de acordo com a sua habilidade cognitiva. Assim continuou a investigação do sistema educativo de toda a instituição de ensino, para saber as ações para a educação especial contidas no Projeto Político Pedagógico, na Proposta Pedagógica para a Educação Inclusiva, os referenciais para a educação inclusiva, para atender ao novo modelo de atendimento ao aluno portador de necessidade especial da Escola da Educação Básica.

Nessa perspectiva, essa pesquisa revelou os diferentes perfis dos professores e alunos com necessidades especiais que necessitam de inclusão e o perfil do professor que se identificam ser capaz de mediar o ensino aprendizagem tanto com o aluno regular e o aluno portador de necessidade especial na mesma sala de aula. Isto, por que a escola começou a direcionar um novo olhar para a inclusão, entender, que, se faz necessário trabalhar a inclusão demonstrando competência, afetividade e valorizando a realidade de cada sujeito, assim como ele é fruto do meio social e precisa construir valores no meio social.

Nessa perspectiva, concorda-se com Freire (1987) "Ninguém educa ninguém, ninguém educa a si mesmo, os homens se educam entre si, no círculo de cultura, a rigor, não se ensina, aprende-se em reciprocidade de como as pessoas, como seres para si, não teria significado". Pois somente adquirindo o princípio do convívio social na sala de aula, o aluno portador de necessidade especial passa compreender que ele é um ser social, capaz de aprender com os colegas, capaz de compreender a mediação do professor em busca do conhecimento que transfere inclusão e participação dos alunos nas construções do dia a dia na sala regular.

\section{REFERÊNCIAS}

ALVES Fátima: Inclusão: muitos olhares, vários caminhos e um grande desafio. 5. Ed. Rio de Janeiro: Wak Editora, 2012.

\section{BRASIL. Lei de Diretrizes e Bases da}

Educação Nacional. Lei No 9394/96, de 20 de dezembro de 1996. Estabelece as diretrizes e bases da educação nacional. São Paulo: Brasil, 1996.

\section{CARVALHO, Rosita Edler, Escola}

inclusiva: a reorganização do trabalho pedagógico $-5^{\mathrm{a}} \mathrm{Ed}$. - Porto Alegre: Mediação, 2012.

CIDEB/MEC: Inclusão: Revista da Educação Especial/Secretaria de Educação Especial. V.5, N 1 (Jan/Jul) - Brasília: Secretaria de Educação Especial, 2010. 
Declaração de Salamanca. Disponível em: http//portal do mec.gov.br/pdf. Acesso em: 9 mar. 2014.

EMILIO, Solange Aparecida. Grupos e

inclusão escolar: sobre laços, amarras e nós São Paulo: Paulus, 2008.

FREIRE, Paulo. Pedagogia do Oprimido, $17^{\mathrm{a}}$ Edição. Paz e Terra, rio de Janeiro, 1987.

MANTOAN, Maria Teresa Eglér. Inclusão Escolar: O que é? Por Quê? Como fazer? São Paulo: Moderna, 2003.

MAZZOTTA, Marcos José Silveira, Educação Especial no Brasil: Historia e

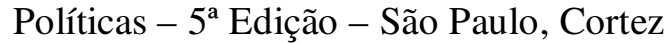
2005. 